\title{
Rheumatoid Hand Surgery in the Era of Biologic Therapy: A Rheumatologist-oriented Overview
}

\author{
Jin Woo Park, M.D. ${ }^{1}$, Ji Sup Hwang, M.D. ${ }^{2}$, Hyun Sik Gong, M.D., Ph.D. ${ }^{2}$ \\ ${ }^{1}$ Department of Orthopedic Surgery, Kangwon National University Hospital, Kangwon National University College of Medicine, Chuncheon, \\ ${ }^{2}$ Department of Orthopedic Surgery, Seoul National University Bundang Hospital, Seoul National University College of Medicine, Seongnam, \\ Korea
}

Rheumatoid arthritis (RA) can cause significant hand and wrist damage and dysfunction. The aim of medical treatment is to eradicate inflammation and prevent damage to joints and soft tissues. Advances in newer biological therapies over the last two decades have resulted in greater remission rates and lower disease activity status. Despite these improvements, surgical intervention is still indicated in cases of disability, irreversible deformities, and severe pain. However, there are large variations in the surgical rates of common rheumatoid hand procedures, which may indicate clinical uncertainty or disagreement between treating rheumatologists and hand surgeons. In this review, we provide a basic overview of common problems of the hand and wrist in RA patients. The target audience is rheumatologists for their better understanding of surgical options and for better informed patient consultation before referring to hand surgeons. (J Rheum Dis 2021;28:192-201)

Key Words. Rheumatoid arthritis, Biologic therapy, Surgery, Hand, Wrist

\section{INTRODUCTION}

Rheumatoid arthritis (RA) is a chronic immune-mediated inflammatory condition which involves polyarticular synovial tissue and results in progressive destruction of joint cartilage [1]. Therapies using disease modifying anti-rheumatic drugs (DMARDs) and currently approved biologics result in rapid improvement in clinical symptoms and can delay radiographic progression [2]. Moreover, early detection of the disease has become possible by better understanding of the pathogenesis [3].

The trend towards earlier and more intensive use of conventional DMARDs and of biological agents have had a huge impact on surgical procedures for patients with RA [4]. Several studies from different countries have reported that the number of orthopedic surgeries for patients with RA has decreased over recent years, indicating a worldwide trend towards improved long-term out- comes of the medications [5-8]. Meanwhile, some studies have reported an increase in the numbers of wrist and finger arthroplasties $[9,10]$. This may be a reflection of reduced disease activity in patients with longstanding RA who now seek better function during activities of daily living. With symptom improvement comes an increase in use of the limbs, from which increased risk of deformity, osteoarthritis and tendon rupture might follow with high probability. Recent evidence demonstrates that most RA patients under drug-induced clinical remission status continue to have "silent synovitis", which is detectable by ultrasound or synovial histology [11].

In RA patients, the metacarpophalangeal, proximal interphalangeal, and wrist joints are involved more frequently than any other joint in the body; up to $70 \%$ of patients develop hand and wrist dysfunction [12]. Joint damage, tenosynovitis, and tendon ruptures are frequent among patients, leading to deformities that prohibit the

Received : May 16, 2021, Revised : June 28, 2021, Accepted : July 12, 2021

Corresponding to : Hyun Sik Gong (iD http://orcid.org/0000-0003-4028-1559

Department of Orthopedic Surgery, Seoul National University Bundang Hospital, Seoul National University College of Medicine, 82 Gumi-ro 173beon-gil, Bundang-gu, Seongnam 13620, Korea. E-mail : hsgong@snu.ac.kr

Copyright (c) 2021 by The Korean College of Rheumatology.

This is an Open Access article, which permits unrestricted non-commerical use, distribution, and reproduction in any medium, provided the original work is properly cited. 
ability to grip, grasp, and pinch. Not all of these deformities are indicated for surgical intervention, as patients usually learn to cope with the deformity despite gradual loss of function. Some patients might have purely aesthetic concerns without true functional issues. Nevertheless, reconstructive surgical options are available, and if done before any severe deformity exists, the quality of life for a patient is definitely improved at least in the short-term [13].

A close working relationship between rheumatologists and hand surgeons is of paramount importance to best treat patients with RA. The patient can only benefit when the physician is better equipped with knowledge about surgical options, because most patients rely on their physicians for information about their disease. The purpose of this review is to provide a simple physician-oriented overview of hand and wrist problems in RA patients so that rheumatologists can better understand the key concepts of surgical options and provide patients with basic information before referring to hand surgeons.

\section{Tendon ruptures}

Tendon rupture is a common complication of RA. Synovitis weakens the substance of tendons, and chronic erosive changes of the joints lead to bony prominences which might cause tendon attrition.

The extensor tendons to the small finger are most at risk due to the erosive synovitis at the dorsal distal radioulnar joint; over time, this will progress radially to finally affect all extensor tendons. Diagnosis of finger extensor tendon rupture requires a thorough physical examination for differential diagnosis with other conditions possible in RA patients. First, metacarpophalangeal (MCP) joint subluxation in ulnar drift hand must be excluded. In this case, the extensor tendon is dislocated, not ruptured. Therefore, patients can maintain their fingers extended once pas-
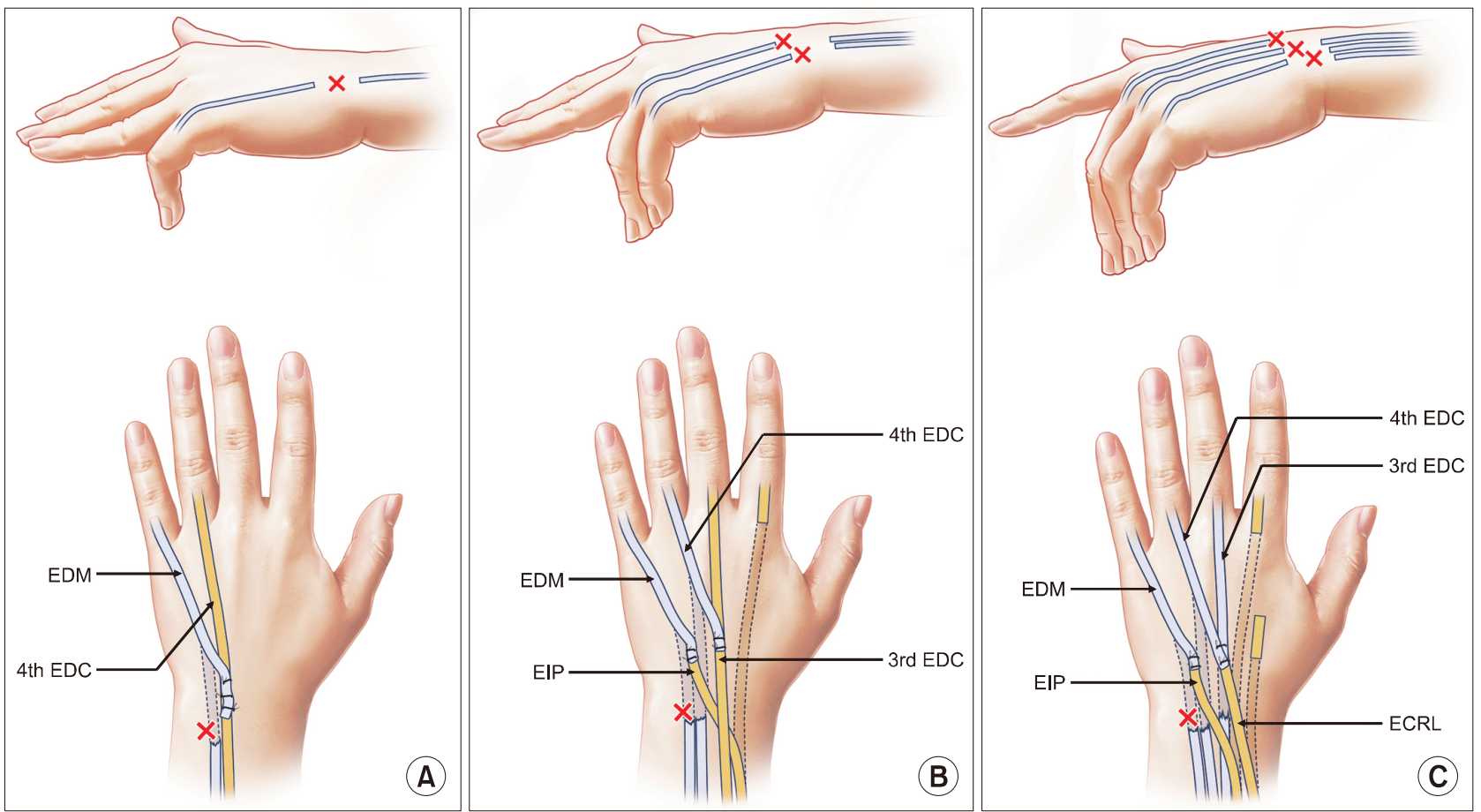

Figure 1. Reconstruction options for ruptured extensor tendon in rheumatoid arthritis according to the involved fingers. (A) For involvement of the little finger only, the extensor digitorum minimi (EDM) function is restored by reattaching its distal part to the 4th extensor digitorum communis (EDC) by end-to-side suture, so that the 4th EDC can extend both the 4th and 5th fingers. (B) For involvement of the little and 4th finger, the 4th EDC function is restored by reattaching its distal part to the 3rd EDC by end-to-side suture, so that the 3rd EDC can extend both the 3rd and 4th fingers. The EDM function is restored by transferring the extensor indicis proprius (EIP) by end-to-end suture, so that the EIP can extend the little finger instead of the index finger. The remaining $2 \mathrm{nd} \mathrm{EDC} \mathrm{ex-}$ tends the index finger without the EIP. (C) Involvement of the little, 4th, and 3rd finger is difficult to treat satisfactorily. The authors' favorite method is to restore the EDM function by transferring the EIP to the EDM by end-to-end repair, and to restore the 3rd and 4th EDCs by transferring the extensor carpi radialis longus (ECRL, wrist extensor) by end-to-end suture (Drawings are authors' own artwork). 
sively extended by an examiner. Secondly, synovitis at the elbow joint can cause a posterior interosseous nerve (PIN) palsy which will cause weakness of finger extension. This PIN palsy should be checked by means of a tenodesis test; passive flexion of the wrist will cause passive finger extension if the tendons are intact.

Extensor tendon ruptures can be reconstructed by tendon transfer, tendon grafting or end-to-side suturing of adjacent tendons (Figure 1). Primary end-to-end repair is not desirable because the ends of the tendon are frayed from inflammation and the proximal motor unit has already developed contractures. To prevent recurrent ruptures, the preexisting synovitis, osseous irritations, and dorsally subluxed ulnar head should be addressed in the way of debridement or formal Darrach or Sauvé-Kapandji (SK) procedures (Figure 2).

Flexor tendon ruptures are much less common than extensor tendon ruptures. Attritional damage from bony spurs at the thumb scaphotrapezial joint in advanced RA can be a cause [14]. Ruptures are frequently associated with compressive neuropathies, and initial presentation with trigger fingers is also frequently seen [15]. The most commonly involved flexor tendon is flexor pollicis longus (FPL), followed by flexor digitorum profundus to the index finger.

Surgical patient selection and counseling: An isolated extensor tendon rupture of the little finger may not result in significant functional limitation, but the patient should be advised to undergo surgery to prevent additional ten- don ruptures and irreversible contracture of the intrinsic muscles due to flexed MCP posture. Patient satisfaction after surgical treatment for multiple tendon ruptures is lower than in cases with a single tendon rupture [16]. In multiple ruptures involving three or more extensor tendons, limitation of available donor muscles results in weak extension strength, and intrinsic muscle contracture can result in limited finger flexion [17]. The best treatment for tendon rupture may be prophylactic management such as extended tenosynovectomy to prevent further damage to the tendons. A number of reports have identified several risk factors associated with higher rates of tendon rupture, which are dorsal dislocation of the distal ulna, carpal collapse, presence of the scallop sign (an erosive change in the distal radioulnar joint) on X-rays, and swelling of the extensor compartments [18-20].

FPL rupture leads to significant functional disability of the thumb, which also necessitates surgical intervention. In RA patients with symptoms of carpal tunnel syndrome and impaired grasping function, flexor tenosynovectomy may be indicated not only to alleviate the symptoms, but also to prevent subsequent tendon ruptures.

Patients need to be informed that healing of the reconstructed tendons generally requires two to four months, and full recovery of strength and motion can take more than six months [21].

\section{Ulnar wrist problems}

Distal radioulnar joint (DRUJ) arthritis is a common cause of ulnar wrist pain in RA. The joint is affected early

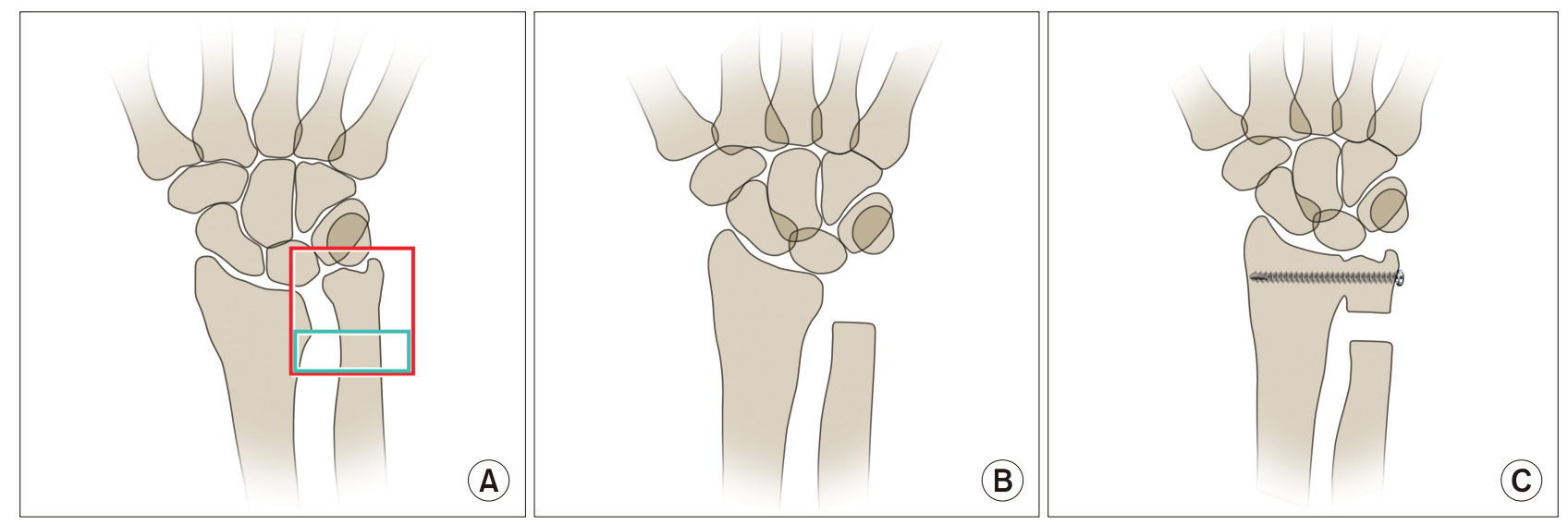

Figure 2. (A) Arthritic change in the distal radioulnar joint results in dorsal subluxation of the ulnar head or ulnocarpal impingement. (B) In the Darrach procedure, the ulnar head is resected and the proximal stump is stabilized by extensor carpi ulnaris. (C) In the Sauvé-Kapandji procedure, the ulnar support of the wrist is preserved by arthrodesis of the distal radioulnar joint. The resection of the ulna is made proximal to the arthrodesis, which creates a pseudarthrosis to allow forearm rotation (Drawings are authors' own artwork). 
in the disease causing painful forearm rotation, instability, and dorsal subluxation of the distal ulna. The prominent ulnar head abuts the carpus, leading to ulnocarpal impingement. Surgical options include resection of the distal ulna (the Darrach procedure) and the SK procedure (Figure 2). Long-term outcomes of Darrach resection show significant pain reduction and functional improvement [22,23]. However, there are some concerns such as increased instability of the wrist and potential ulnar translation of the carpus [24]. Alternatively, the SK procedure fuses the DRUJ to prevent ulnar translation of the carpus while also performing a proximal ulna ostectomy to maintain some rotatory function. Complications include instability of the proximal ulnar stump and nonunion of the fusion site [25]. Outcomes of the two procedures have been equally satisfactory in the rheumatoid population [26].

The extensor carpi ulnaris (ECU) tendon is one of the most frequently involved tendons in RA [27]. In some RA patients, synovial thickening of the ECU subsheath may lead to its destruction and eventual volar dislocation of the ECU proper. Findings have suggested that tenosynovitis of the ECU tendon can be a predictor of erosive progression in early RA [28]. Surgical options include simple ECU synovectomy, relocation of the tendon, and bony procedures if necessary.

The triangular fibrocartilage complex (TFCC), which is a load-bearing structure for the ulnocarpal joint and a primary stabilizer of the DRUJ, is progressively destroyed in RA. This situation can lead to instability, pain, and mechanical symptoms. With the trend toward milder disease activity due to improved medical therapies, patients with TFCC tears can benefit from arthroscopic synovectomy or repair of the TFCC, before any significant arthritic changes accompany.

Surgical patient selection and counseling: Surgical treatment for DRUJ arthritis should be recommended for patients with intractable pain, limitation of forearm rotation, or extensor tendon ruptures. The DRUJ procedures (Darrach or SK procedures, Figure 2) are an effective and rewarding surgery, and are less invasive compared to total arthrodesis or replacement arthroplasties of other large joints. The authors prefer a Darrach procedure in low-demand elderly patients while the SK procedure is selected for high-demand young patients with a risk of ulnar translocation of the carpus.

\section{Dorsal wrist problems}

Common dorsal wrist problems are synovitis of extensor tendons and/or synovitis of the radiocarpal or midcarpal joints. Dorsal synovitis is generally more recognized than volar synovitis, because the dorsal synovium is placed more superficially. Synovitis of extensor tendons needs tenosynovectomy through an open incision, while synovitis limited to radiocarpal or midcarpal joints can be treated with arthroscopic synovectomy. Arthroscopic procedures can be simply performed for synovial biopsy, which aids in accurate diagnosis by exclusion of other chronic inflammatory disorders or infection.

Synovectomy of the joint is most appropriate when joint motion is still relatively well preserved [29]. On the other hand, advanced arthritis with severe joint destruction and instability can be treated with arthrodesis or arthroplasty. In patients with disease localized to the radiocarpal joint and progressive ulnar translocation of the carpus, limited wrist arthrodesis such as radiolunate or radioscapholunate arthrodesis has shown good outcomes at mid- and long-term follow-up [30,31]. Through the procedure, partial wrist motion and bone stock are preserved while disease progression is prohibited (Figure 3). There is an objective and subjective increase in grip strength while pain relief is also achieved [32]. Progression of arthritic changes at the midcarpal joint following partial wrist fusion is generally well tolerated [33]. Total wrist arthrodesis is the procedure of choice in advanced or diffuse arthritis of the wrist with severe pain, deformity, and poor
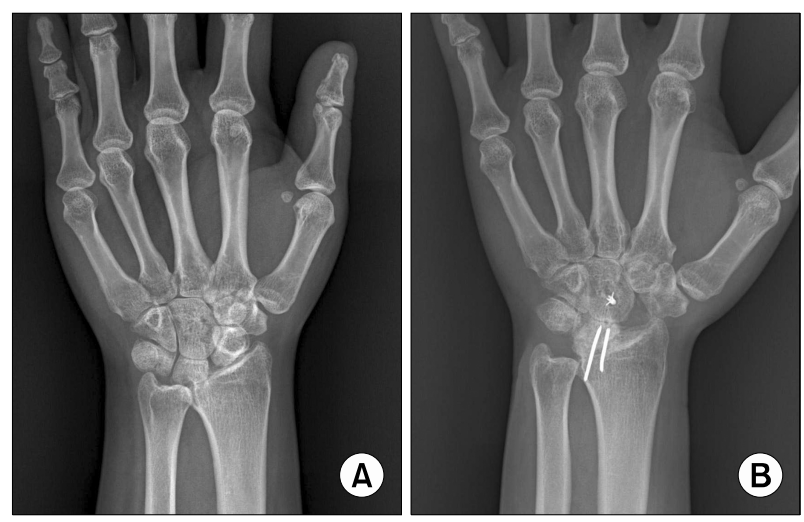

Figure 3. (A) The carpal bones have migrated ulnarly with arthritic changes mainly in the radiocarpal joint, with relatively preserved midcarpal joint. (B) The scaphoid was resected and arthrodesis was done between the lunate and the radius (radiolunate fusion) so that the carpal bones do not migrate further ulnarly. Partial wrist motion can occur in the midcarpal joint. 
soft tissue support, but the necessity of this procedure is decreasing. The obvious drawback to this procedure is loss of wrist motion. It is important that the patients understand this, although, in most situations, a pain-free and stable wrist can overweigh this drawback.

Total wrist arthroplasty is an alternative to arthrodesis and has the advantage of preserving wrist motion. Disadvantages lie in the durability and reliability of the implant. Systematic reviews comparing wrist arthrodesis with wrist arthroplasty in RA patients show that pain relief is achieved after both procedures, but with higher complication rates after arthroplasty than arthrodesis [34]. Stable wrists with preserved bone stock is a good indication for arthroplasty and good results can be expected even in the long-term $[35,36]$. When done successfully, patients prefer arthroplasty to arthrodesis because of improved ease of activities of daily living [37]. Further longer-term studies will be needed to better define the role of arthroplasty in the management of wrist RA.

\section{Surgical patient selection and counseling: Extensor te-} nosynovectomy is recommended to prevent tendon ruptures, which is possible when synovitis persists for more than four to six months of medical therapies [20]. In some patients with synovitis of the wrist, systematic inflammation might be well controlled by medical treatment. For these patients, arthroscopic synovectomy can be helpful for debulking the synovitis and for maintaining the dose of current medical treatment [38]. The patients should be informed that synovectomy procedures are prophylactic and not curative; although the short-term benefits, such as pain relief and improved function, are fairly reliable, it does not correlate with long-term disease remission and retardation of joint destruction $[39,40]$.

For the patient with persistent, debilitating pain and advanced wear of the radiocarpal joint, surgical options are relatively straightforward; either arthrodesis or arthroplasty.

\section{Ulnar drift hand}

The prognosis of RA often includes hand deformities, with ulnar drift being the most common. It is secondary to chronic proliferative synovitis of the MCP joints which causes attenuation of the radial collateral ligament and radial portion of the sagittal band of the extensor apparatus. The extensor tendons displace ulnarly, the proximal phalanges subluxate volarly and intrinsic contractures develop in a compensatory manner (Figure 4).
Fine pinch is hampered and patients find it difficult to curl the fingers around large objects. Another very important concern for patients is the unappealing appearance; studies have shown that aesthetics along with function are major factors that influence patients' decision to undergo surgery [41].

In early stage of the deformity, synovectomy of the MCP joint, coupled with extensor tendon centralization and a cross-intrinsic transfer, is a good surgical option to restore the normal position of the fingers (Figure 5, Supplementary Video 1 and 2). For patients with chronic MCP joint subluxation or joint destruction, soft tissue reconstruction alone may not correct the deformity, and arthroplasty is needed. MCP joint arthroplasty has been one of the most commonly performed surgical procedures on the hand for RA patients in the developed countries [42]. Constrained silicone implants have been used for decades and are still the most commonly used material for replacement of MCP joints destroyed by RA. These implants act as an interpositional spacer which help align the joint in proper position. According to a multicenter prospective cohort study, subjects who underwent silicone metacarpophalangeal joint arthroplasty showed better outcomes at seven-year follow-up in function, aesthetics and satisfaction, when compared to the medically managed group [43].

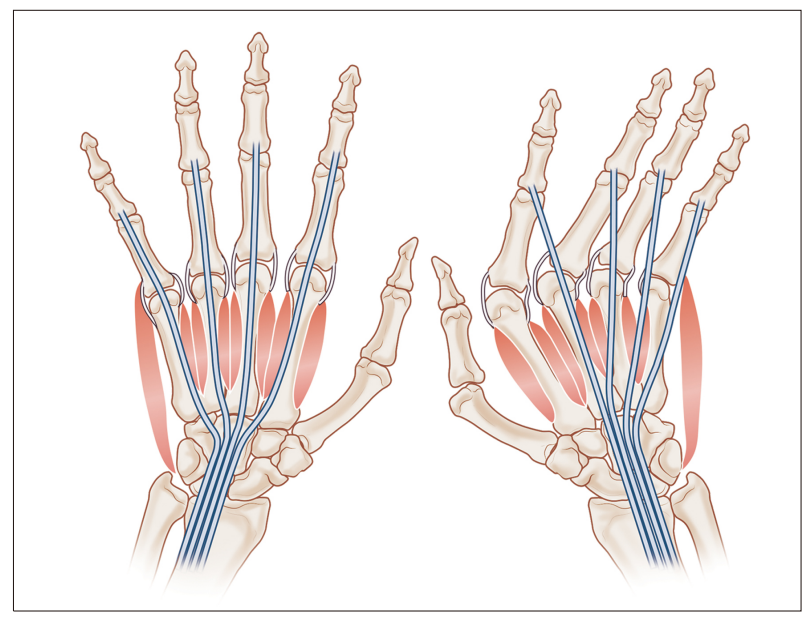

Figure 4. In rheumatoid arthritis hand, synovitis at the metacarpophalangeal joint destructs stabilizing ligaments, which results in extensor tendon displacement ulnarly. Moreover, the proximal phalanx subluxates in a volar direction and contracture of intrinsic muscles of the hand results in permanent flexion deformities. The deformity can deteriorate one's quality of life by affecting hand grip function and by causing cosmetic problems (Drawings are authors' own artwork). 


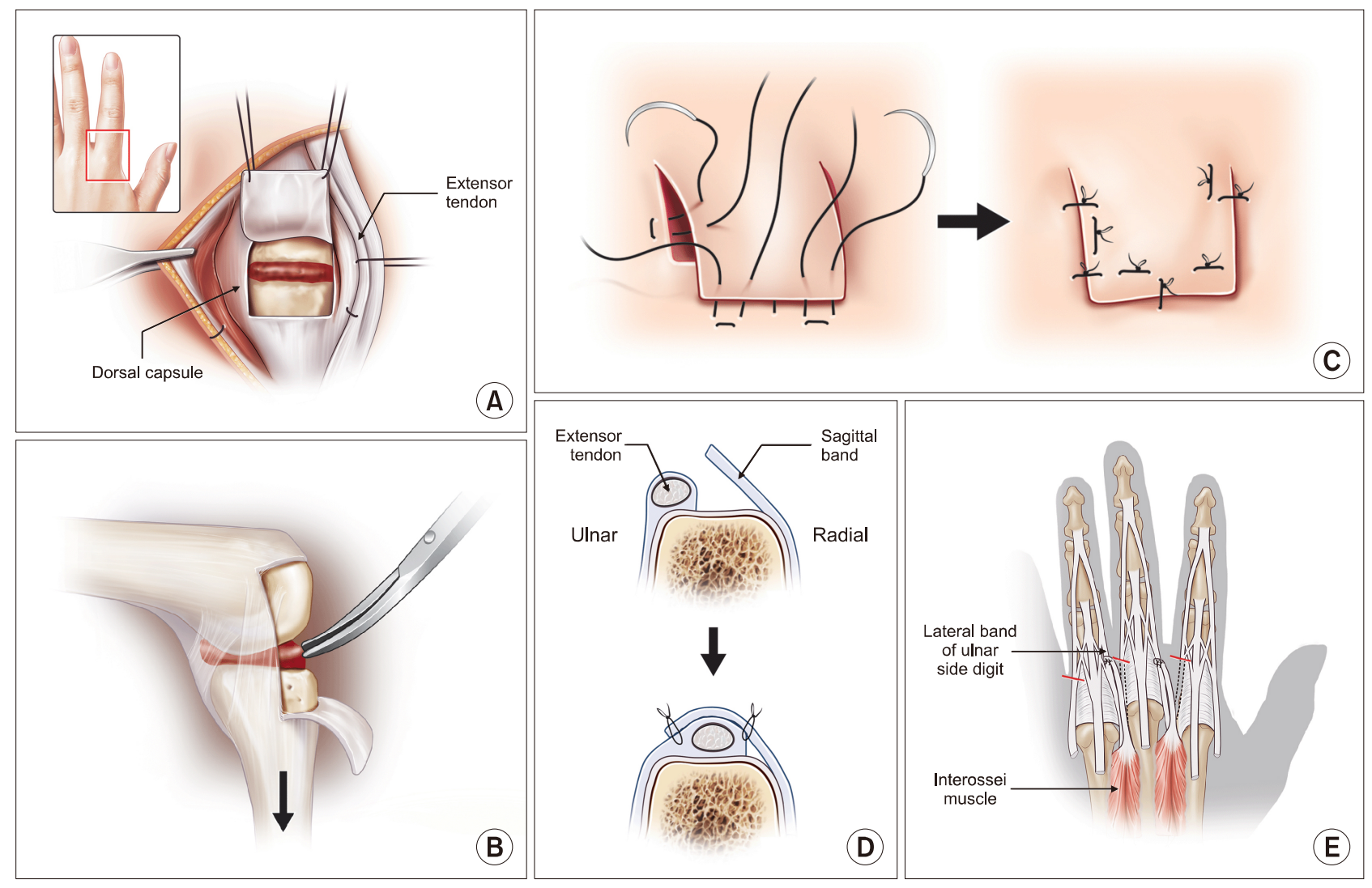

Figure 5. For early stages of ulnar drift hand deformity, the following procedures aim to restore the normal position of the fingers. Through a square bracket-shaped incision at dorsal capsule of the metacarpophalangeal joint (A), a thorough synovectomy of the joint is performed (B), followed by plication of the capsule (C). (D) The subluxated extensor tendon is divided longitudinally on the radial side of sagittal band, relocated to the normal site, and plicated. (E) The intrinsic tendons at ulnar side are detached and transferred to the radial side of the next finger, thus changing a deforming force into a correcting force (Drawings are authors' own artwork).

Surgical patient selection and counseling: Soft tissue reconstruction for ulnar drift hand can be performed with good functional and aesthetic outcomes and with less invasiveness. The procedure offers an opportunity to perform synovectomy and correct the ulnar drift deformity before progression of more severe skeletal damage. Deformity alone should not be an indication for recommending surgical treatment, but for some patients, aesthetics is the main concern and improving the appearance of the typical ulnar drift may be beneficial to the patient's self-regard. Similar to the synovectomy for the wrist joint, the patient should be reminded that soft tissue reconstruction is not curative, and recurrence can occur if medical treatment fails to control inflammation.

\section{Swan-neck and boutonniere deformities}

The proximal interphalangeal (PIP) joints and distal interphalangeal (DIP) joints are less commonly involved in
RA. The two common digital deformities are swan-neck and boutonniere deformities.

Deformities that are flexible can be treated by conservative treatment using a figure-eight ring for swanneck deformity and extension splinting for boutonniere deformity. Soft tissue reconstruction procedures include flexor digitorum superficialis tenodesis, reconstruction of the oblique retinacular ligament, and volar translocation of the lateral bands for swan-neck deformity [44-46], and reconstruction of the central slip and repositioning of the lateral bands dorsally for boutonniere deformity. For severe arthritic joints, arthrodesis or arthroplasty can be performed.

Surgical patient selection and counseling: Patients with swan-neck deformity can have functional problems as they are unable to make a full fist due to the hyperextended PIP joint. However, in patients with bou- 
tonniere deformity, their capacity to make a full fist is maintained, and the unappealing appearance of the finger is more of concern to the patient. In the authors' experience, soft tissue reconstruction for swan-neck deformity can be helpful for patients' hand function, but surgical correction of boutonniere deformity is difficult and may not fulfill patients' expectation for cosmetic appearance.

\section{Thumb deformities}

The two most common thumb deformities in RA are also boutonniere deformity and swan-neck deformity. Boutonniere deformity of the thumb consists of flexed MCP joint and hyperextended interphalangeal (IP) joint. Progressive synovitis attenuates the dorsal capsule and causes volar and ulnar subluxation of the EPL tendon, which results in volar subluxation of the MCP joint. On the other hand, swan-neck deformity develops mainly due to synovitis and dorsoradial subluxation at the trapeziometacarpal (TMC) joint with resultant metacarpal adduction. Progressive adduction and flexion of the metacarpal results in secondary hyperextension of MCP joint and flexion of IP joint (Figure 6).

\section{Surgical patient selection and counseling:}

The thumb constitutes approximately $50 \%$ of hand function. Therefore, the most important part of rheumatoid hand surgery is to reconstruct the thumb to improve pinch and grip, appearance, and posture. In the authors' experience, for severe boutonniere deformity with hyperextension or deviation of the IP joint, arthrodesis of the IP joint is a simple and effective solution. Severe deformity at TMC joint can also be managed with simple trapeziectomy (Figure 6).

\section{CONCLUSION}

The availability of targeted pharmacotherapies for RA has provided rheumatologists the opportunity to improve RA treatment. Despite greatly improved disease control, there will always be a need for surgery as a substantial number of patients may not be responsive to medications. Motivated patients with higher quality of life due to new medications have higher expectations on the functionality and appearance of their hands and may seek surgical assistance more often.

In the authors' experience, reconstruction of tendon ruptures and the DRUJ along with correction of ulnar drift and thumb deformities have been the most rewarding, because they improve a patient's self-regard and the ability to function in everyday life.

Surgical referral does not mean planning for immediate surgery but it can be an early introduction to a hand surgeon who can inform patients of available options. Careful planning of a number of available surgical treatments (Table 1) can maintain patients' hand function and should enhance outcomes by correcting existing deformities.
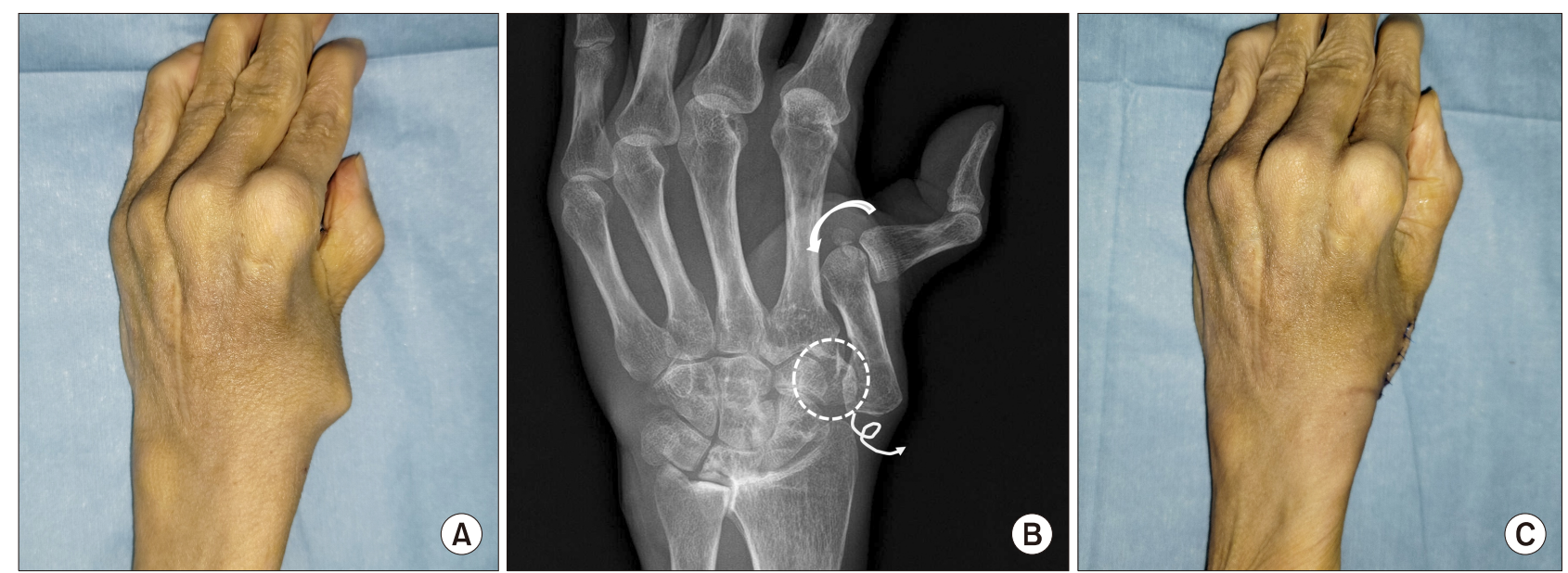

Figure 6. (A) This patient presented with swan neck deformity of the thumb. In this type of deformity, the metacarpal bone is progressively adducted and flexed, which results in inconvenience in opening of the first webspace. (B) The radiograph shows dorsoradial subluxation of the trapeziometacarpal (TMC) joint indicative of severe synovitis, and resultant metacarpal adduction and compensatory hyperextension of the metacarpophalangeal (MCP) joint (zigzag deformity). Resection of the trapezium (dotted circle) and volar capsulodesis of the MCP joint (curved arrow) was performed. (C) Deformities of the TMC and MCP joints were corrected. Improved thumb abduction and pinching was observed along with cosmetic improvement. 
Table 1. Summary of common procedures of the rheumatoid hand

\begin{tabular}{|c|c|c|}
\hline Procedure & Indications & Description/Outcomes \\
\hline \multicolumn{3}{|l|}{ Preventive procedures } \\
\hline Synovectomy and/or tenosynovectomy & $\begin{array}{l}\text { Persistent wrist synovitis in the early } \\
\text { stages of the disease with moderate } \\
\text { swelling and relatively well preserved } \\
\text { joint motion }\end{array}$ & $\begin{array}{l}\text { Short-term benefits, such as pain relief and } \\
\text { improved function }\end{array}$ \\
\hline \multicolumn{3}{|l|}{ Ulnar wrist-related } \\
\hline Darrach procedure & $\begin{array}{l}\text { Pain from DRUJ disease and distal ulna } \\
\text { impingement on the carpus }\end{array}$ & $\begin{array}{l}\text { Long-term improvement in pain and } \\
\text { function/risk of potential ulnar } \\
\text { translocation of the carpus }\end{array}$ \\
\hline Sauvé-Kapandji procedure & Same as above & $\begin{array}{l}\text { Support to ulnar carpus/unpredictable } \\
\text { fusion of DRUJ }\end{array}$ \\
\hline \multicolumn{3}{|l|}{ Dorsal wrist-related } \\
\hline Partial wrist arthrodesis & $\begin{array}{l}\text { Disease primarily localized to } \\
\text { radiocarpal joint while sparing the } \\
\text { midcarpal joint }\end{array}$ & $\begin{array}{l}\text { Preserves some range of motion of the } \\
\text { wrist/generally reliable outcomes with } \\
\text { low rates of nonunion }\end{array}$ \\
\hline Total wrist arthrodesis & $\begin{array}{l}\text { Pan-carpal arthritis with poor tissue } \\
\text { support }\end{array}$ & $\begin{array}{l}\text { Significant limitation of wrist } \\
\text { motion/generally excellent clinical } \\
\text { outcomes }\end{array}$ \\
\hline Total wrist arthroplasty & $\begin{array}{l}\text { Pan-carpal arthritis/alternative to total } \\
\text { arthrodesis }\end{array}$ & $\begin{array}{l}\text { High-risk, high-reward procedure with } \\
\text { preservation of wrist motion but } \\
\text { questions in durability and reliability }\end{array}$ \\
\hline \multicolumn{3}{|l|}{ Ulnar drift deformity } \\
\hline Extensor tendon centralization & $\begin{array}{l}\text { Extensor subluxation with resultant } \\
\text { ulnar drift deformity }\end{array}$ & Centralization with soft-tissue balancing \\
\hline Cross-intrinsic transfer & $\begin{array}{l}\text { Ulnar drift deformity with volar } \\
\text { subluxation of MCP joint }\end{array}$ & $\begin{array}{l}\text { Transfer of intrinsic muscles to radial side } \\
\text { to provide radial stability }\end{array}$ \\
\hline Joint arthroplasty & Damage of articular surface & $\begin{array}{l}\text { Proper joint alignment/improvement in } \\
\text { function and aesthetics }\end{array}$ \\
\hline \multicolumn{3}{|l|}{ Swan-neck deformities } \\
\hline FDS tenodesis & $\begin{array}{l}\text { Flexible hyperextension deformity of } \\
\text { PIP joint }\end{array}$ & $\begin{array}{l}\text { Static volar restraint against } \\
\text { hyperextension/Improved initiation of } \\
\text { PIP flexion }\end{array}$ \\
\hline $\begin{array}{l}\text { Reconstruction of oblique retinacular } \\
\text { ligament }\end{array}$ & Same as above & $\begin{array}{l}\text { Dynamic tenodesis/restores DIP extension } \\
\text { and restrains PIP hyperextension } \\
\text { simultaneously }\end{array}$ \\
\hline Volar translocation of lateral bands & $\begin{array}{l}\text { Early flexible SND caused by PIP } \\
\text { synovitis }\end{array}$ & $\begin{array}{l}\text { Minimally invasive/effective and sustained } \\
\text { correction }\end{array}$ \\
\hline Trapeziectomy & SND of the thumb & $\begin{array}{l}\text { Simple trapezium excision to various } \\
\text { resection suspension arthroplasties }\end{array}$ \\
\hline \multicolumn{3}{|l|}{ Boutonniere deformities } \\
\hline $\begin{array}{l}\text { Central slip shortening and dorsal } \\
\text { repositioning of lateral bands }\end{array}$ & $\begin{array}{l}\text { DIP hyperextension with preserved } \\
\text { PIP joint cartilage }\end{array}$ & $\begin{array}{l}\text { Excision of redundant central slip and } \\
\text { advancement/mobilization and dorsal } \\
\text { repositioning of lateral bands }\end{array}$ \\
\hline Arthrodesis & $\begin{array}{l}\text { Articular destruction or severe flexion } \\
\text { contracture of PIP joint/thumb IP joint }\end{array}$ & $\begin{array}{l}\text { Simple and reliable option for managing } \\
\text { pain and treating deformity }\end{array}$ \\
\hline
\end{tabular}

DIP: distal interphalangeal, DRUJ: distal radioulnar joint, FDS: flexor digitorum superficialis, MCP: metacarpophalangeal, PIP: proximal interphalangeal, SND: swan-neck deformity. 


\section{SUPPLEMENTARY DATA}

Supplementary data can be found with this article online at https://doi.org/10.4078/jrd.2021.28.4.192.

\section{CONFLICT OF INTEREST}

No potential conflict of interest relevant to this article was reported.

\section{AUTHOR CONTRIBUTIONS}

Among the authors, J.W.P. was responsible for analysis and/or interpretation of data and drafting the manuscript. J.S.H. was responsible for acquisition of data and drafting the manuscript. H.S.G. was in charge of conception and design of study and revising the manuscript critically for important intellectual content.

\section{REFERENCES}

1. McInnes IB, Schett G. The pathogenesis of rheumatoid arthritis. N Engl J Med 2011;365:2205-19.

2. Aletaha D, Smolen JS. Diagnosis and management of rheumatoid arthritis: a review. JAMA 2018;320:1360-72.

3. Grigor C, Capell H, Stirling A, McMahon AD, Lock P, Vallance R, et al. Effect of a treatment strategy of tight control for rheumatoid arthritis (the TICORA study): a single-blind randomised controlled trial. Lancet 2004;364: 263-9.

4. Chung KC, Pushman AG. Current concepts in the management of the rheumatoid hand. J Hand Surg Am 2011; 36:736-47.

5. Fevang BT, Lie SA, Havelin LI, Engesaeter LB, Furnes O. Reduction in orthopedic surgery among patients with chronic inflammatory joint disease in Norway, 1994-2004. Arthritis Rheum 2007;57:529-32.

6. Kievit W, Fransen J, de Waal Malefijt MC, den Broeder AA, van Riel PL. Treatment changes and improved outcomes in RA: an overview of a large inception cohort from 1989 to 2009. Rheumatology (Oxford) 2013;52:1500-8.

7. Louie GH, Ward MM. Changes in the rates of joint surgery among patients with rheumatoid arthritis in California, 1983-2007. Ann Rheum Dis 2010;69:868-71.

8. Dafydd M, Whitaker IS, Murison MS, Boyce DE. Change in operative workload for rheumatoid disease of the hand: 1,109 procedures over 13 years. J Plast Reconstr Aesthet Surg 2012;65:800-3.

9. Momohara S, Inoue E, Ikari K, Ochi K, Ishida O, Yano K, et al. Recent trends in orthopedic surgery aiming to improve quality of life for those with rheumatoid arthritis: data from a large observational cohort. J Rheumatol 2014;41:862-6.

10. Weiss RJ, Ehlin A, Montgomery SM, Wick MC, Stark A, Wretenberg P. Decrease of RA-related orthopaedic surgery of the upper limbs between 1998 and 2004: data from
54,579 Swedish RA inpatients. Rheumatology (Oxford) 2008;47:491-4.

11. Saleem B, Brown AK, Keen H, Nizam S, Freeston J, Karim Z, et al. Disease remission state in patients treated with the combination of tumor necrosis factor blockade and methotrexate or with disease-modifying antirheumatic drugs: a clinical and imaging comparative study. Arthritis Rheum 2009;60:1915-22.

12. de la Mata Llord J, Palacios Carvajal J. Rheumatoid arthritis: are outcomes better with medical or surgical management? Orthopedics 1998;21:1085-6.

13. Chung KC, Burns PB, Wilgis EF, Burke FD, Regan M, Kim $\mathrm{HM}$, et al. A multicenter clinical trial in rheumatoid arthritis comparing silicone metacarpophalangeal joint arthroplasty with medical treatment. J Hand Surg Am 2009;34:815-23.

14. Simmen BR, Kolling C, Herren DB. (iv) The management of the rheumatoid wrist. Curr Orthop 2007;21:344-57.

15. Schindele SF, Herren DB, Simmen BR. Tendon reconstruction for the rheumatoid hand. Hand Clin 2011;27: 105-13.

16. Shannon FT, Barton NJ. Surgery for rupture of extensor tendons in rheumatoid arthritis. Hand 1976;8:279-86.

17. Nakamura S, Katsuki M. Tendon grafting for multiple extensor tendon ruptures of fingers in rheumatoid hands. J Hand Surg Br 2002;27:326-8.

18. Asano K, Shinohara T, Iwatsuki K, Yamamoto M, Tatebe M, Hirata $\mathrm{H}$. Risk factors for rupture of extensor tendons in the rheumatoid wrist. J Hand Surg Eur Vol 2020;45:1087-92.

19. Hsueh JH, Liu WC, Yang KC, Hsu KC, Lin CT, Chen LW. Spontaneous extensor tendon rupture in the rheumatoid wrist: risk factors and preventive role of extended tenosynovectomy. Ann Plast Surg 2016;76 Suppl 1:S41-7.

20. Ryu J, Saito S, Honda T, Yamamoto K. Risk factors and prophylactic tenosynovectomy for extensor tendon ruptures in the rheumatoid hand. J Hand Surg Br 1998;23:658-61.

21. The British Society for Surgery of the Hand. Flexor tendon injury [Internet]. London: The British Society for Surgery of the Hand, 2016 [cited 2021 Apr 3]. Available from: https://www.bssh.ac.uk/patients/conditions/26/flexor tendon_injury.

22. Jain A, Ball C, Freidin AJ, Nanchahal J. Effects of extensor synovectomy and excision of the distal ulna in rheumatoid arthritis on long-term function. J Hand Surg Am 2010;35: 1442-8.

23. Van Gemert AM, Spauwen PH. Radiological evaluation of the long-term effects of resection of the distal ulna in rheumatoid arthritis. J Hand Surg Br 1994;19:330-3.

24. Bieber EJ, Linscheid RL, Dobyns JH, Beckenbaugh RD. Failed distal ulna resections. J Hand Surg Am 1988;13: 193-200.

25. Condamine JL, Lebreton L, Aubriot JH. [The SauvéKapandji operation. Analysis and results of 69 cases]. Ann Chir Main Memb Super 1992;11:27-39. French.

26. Kobayashi A, Futami T, Tadano I, Fujita M, Watanabe T, Moriguchi T. Radiographic comparative evaluation of the Sauve-Kapandji procedure and the Darrach procedure for rheumatoid wrist reconstruction. Mod Rheumatol 2005;15: 187-90.

27. McQueen F, Beckley V, Crabbe J, Robinson E, Yeoman S, Stewart N. Magnetic resonance imaging evidence of tendinopathy in early rheumatoid arthritis predicts tendon rup- 
ture at six years. Arthritis Rheum 2005;52:744-51.

28. Lillegraven S, Bøyesen P, Hammer HB, Østergaard M, Uhlig $\mathrm{T}$, Sesseng $\mathrm{S}$, et al. Tenosynovitis of the extensor carpi ulnaris tendon predicts erosive progression in early rheumatoid arthritis. Ann Rheum Dis 2011;70:2049-50.

29. Rizzo M, Cooney WP 3rd. Current concepts and treatment for the rheumatoid wrist. Hand Clin 2011;27:57-72.

30. Honkanen PB, Mäkelä S, Konttinen YT, Lehto MU. Radiocarpal arthrodesis in the treatment of the rheumatoid wrist. A prospective midterm follow-up. J Hand Surg Eur Vol 2007;32:368-76

31. Raven EE, Ottink KD, Doets KC. Radiolunate and radioscapholunate arthrodeses as treatments for rheumatoid and psoriatic arthritis: long-term follow-up. J Hand Surg Am 2012;37:55-62.

32. Ishikawa $\mathrm{H}$, Murasawa $\mathrm{A}$, Nakazono K. Long-term follow-up study of radiocarpal arthrodesis for the rheumatoid wrist. J Hand Surg Am 2005;30:658-66.

33. Borisch N, Haussmann P. Radiolunate arthrodesis in the rheumatoid wrist: a retrospective clinical and radiological longterm follow-up. J Hand Surg Br 2002;27:61-72.

34. Cavaliere CM, Chung KC. A systematic review of total wrist arthroplasty compared with total wrist arthrodesis for rheumatoid arthritis. Plast Reconstr Surg 2008;122:813-25.

35. Bhamra J, Bhamra K, Hindocha S, Khan W. The role of wrist fusion and wrist arthroplasty in rheumatoid arthritis. Curr Rheumatol Rev 2017;13:23-8.

36. Ogunro S, Ahmed I, Tan V. Current indications and outcomes of total wrist arthroplasty. Orthop Clin North Am 2013;44:371-9, ix.

37. Murphy DM, Khoury JG, Imbriglia JE, Adams BD. Comparison of arthroplasty and arthrodesis for the rheumatoid wrist. J Hand Surg Am 2003;28:570-6.
38. Kanbe K, Inoue K. Efficacy of arthroscopic synovectomy for the effect attenuation cases of infliximab in rheumatoid arthritis. Clin Rheumatol 2006;25:877-81.

39. Nakamura H, Nagashima M, Ishigami S, Wauke K, Yoshino $\mathrm{S}$. The anti-rheumatic effect of multiple synovectomy in patients with refractory rheumatoid arthritis. Int Orthop 2000;24:242-5.

40. Ochi T, Iwase R, Kimura T, Hirooka A, Masada K, Owaki H, et al. Effect of early synovectomy on the course of rheumatoid arthritis. J Rheumatol 1991;18:1794-8.

41. Mathews AL, Burns PB, Chung KC. How rheumatoid arthritis patients make decisions regarding hand reconstruction: a qualitative study from the Silicone Arthroplasty in Rheumatoid Arthritis Project. Plast Reconstr Surg 2016; 137:1507-14.

42. Waljee J, Zhong L, Baser O, Yuce H, Fox DA, Chung KC. The incidence of upper and lower extremity surgery for rheumatoid arthritis among Medicare beneficiaries. J Bone Joint Surg Am 2015;97:403-10.

43. Chung KC, Kotsis SV, Burns PB, Burke FD, Wilgis EFS, Fox DA, et al. Seven-year outcomes of the Silicone Arthroplasty in Rheumatoid Arthritis Prospective Cohort Study. Arthritis Care Res (Hoboken) 2017;69:973-81.

44. Brulard C, Sauvage A, Mares O, Wavreille G, Fontaine C. [Treatment of rheumatoid swan neck deformity by tenodesis of proximal interphalangeal joint with a half flexor digitorum superficialis tendon. About 23 fingers at 61 months follow-up]. Chir Main 2012;31:118-27. French.

45. Borisch N, Haubmann P. [Littler tenodesis for correction of swan neck deformity in rheumatoid arthritis]. Oper Orthop Traumatol 2011;23:232-40. German.

46. Tonkin MA, Hughes J, Smith KL. Lateral band translocation for swan-neck deformity. J Hand Surg Am 1992;17:260-7. 